\title{
POLÍTICAS TERRITORIAIS DE DESENVOLVIMENTO RURAL: O PROGRAMA TERRITÓRIOS DA CIDADANIA
}

\author{
Lucélia Maria Gonzaga Bernardes Ferrari ${ }^{1}$ \\ Adão Francisco de Oliveira ${ }^{2}$
}

Resumo: Esse artigo tem por objetivo situar o processo de adoção do enfoque territorial e suas dimensões nas políticas públicas brasileiras. Todavia, delimita sua discussão à dinâmica de implantação das políticas que utilizam o território como fim, ou seja, "políticas baseadas em estratégias intersetoriais e articuladas para 0 desenvolvimento de territórios específicos com graves deficiências estruturais e alta incidência de pobreza" (SILVA, 2013, p. 31). Dessa maneira, o histórico dessa abordagem está restrito, aqui, ao programa federal Territórios da Cidadania (PTC), criado em 2008 pelo governo do presidente Luís Inácio "Lula" da Silva. Metodologicamente, realiza-se uma revisão bibliográfica baseada, focada no método histórico e numa abordagem crítica, com vistas à compreensão da perspectiva territorial nas políticas públicas.

Palavras-chave: Políticas Públicas; Abordagem Territorial; Desenvolvimento Rural; Programa Territórios da Cidadania; Tocantins.

\section{TERRITORIAL POLICIES ON RURAL DEVELOPMENT: THE CITIZENS 'TERRITORIAL PROGRAM}

\begin{abstract}
This article aims to situate the process of adopting the territorial approach and its dimensions in Brazilian public policies. However, it delimits its discussion on the dynamics of implementation of policies that use the territory as an end, that is, "policies based on intersectoral and articulated strategies for the development of specific territories with serious structural deficiencies and a high incidence of poverty" (SILVA, 2013, 31). Thus, the history of this approach is restricted here to the federal Territorial Citizenship Program (PTC), created in 2008 by the government of President Luís Inácio "Lula" da Silva. Methodologically, a bibliographical review based on the historical method and a critical approach is carried out with a view to understanding the territorial perspective in public policies.
\end{abstract}

Keywords: Public Policy; Territorial Approach; Rural Development; Territory of Citizenship Program; Tocantins.

\footnotetext{
${ }^{1}$ Mestre em Geografia pela Universidade Federal do Tocantins (UFT) - Campus de Porto Nacional. luceliaferrari@uft.edu.br. ${ }^{2}$ Docente da Universidade Federal do Tocantins (UFT). adaofrancisco@gmail.com.

Estudos Geográficos, Rio Claro, 17: 116-133, jan./jun. 2019 (ISSN 1678-698X) http://www.periodicos.rc.biblioteca.unesp.br/index.php/estgeo
} 


\section{INTRODUÇÃO}

O Programa Territórios da Cidadania (PTC) é uma política pública brasileira criada em 2008, ainda no primeiro governo do presidente Luis Inácio "Lula" da Silva, em resposta às demandas dos movimentos sociais do campo por políticas públicas voltadas ao atendimento de suas necessidades de recursos, inclusão e participação na construção do desenvolvimento do país, em especial, do desenvolvimento rural. Tais movimentos são constituídos de diversos atores: assentados da reforma agrária, sem-terra, agricultores familiares, extrativistas, ribeirinhos, quilombolas, indígenas, pescadores artesanais e aquicultores, seringueiros, povos da floresta, e outros públicos. O que esses movimentos exigiam era uma mudança de paradigma para a concepção de desenvolvimento e de mundo rural, não mais calcado na agricultura unicamente, nem na priorização das grandes lavouras voltadas à exportação. O que se vislumbrava era a abertura de espaços de participação na construção das políticas públicas, bem como o respeito à diversidade, à sustentabilidade, ao fortalecimento do mercado interno, à reforma agrária na sua ampla acepção e à agricultura familiar. Eis aí os "gritos de ordem".

A abordagem territorial das políticas públicas para desenvolvimento rural no Brasil - tomando-o neste sentido amplo, para além do aspecto exclusivamente agrícola e do papel de equilibrador da balança comercial - é recente (processo democratizante iniciado na década de 1980) e a opção dos governos pela implementação das mesmas com gestão participativa da sociedade é mais recente ainda.

Ao tratar de desenvolvimento rural é importante fazer uma contextualização, pois o conceito de desenvolvimento rural e o conceito de rural não foram, na construção da sociedade brasileira, unânimes e nem pacíficos, e nem tampouco semelhantes nos diversos períodos históricos. Sobre o quê e sobre quem estamos falando quando tratamos do mundo rural em suas dimensões ambiental, econômica, social, cultural e política? É necessário esclarecer.

Segundo Delgado (2009), os distintos conceitos são disputados na luta política por projetos e por concepções alternativas sobre o mundo rural, que darão visibilidade a seus personagens e reconhecimento pela sociedade e pelo Estado, através do acesso a direitos sociais e a políticas públicas. Para ele, a década de 1990 é decisiva para demarcar os termos dessa disputa por um futuro do significado do Brasil rural e do desenvolvimento rural.

O processo de democratização da sociedade brasileira iniciado na década de 1980 proporcionou revitalização do movimento sindical e o surgimento de novos movimentos sociais no campo, complexificaram-se os personagens e as demandas do mundo do trabalho rural e começou a ser elaborada uma crítica contundente ao modelo de modernização agrícola adotado, conhecido internacionalmente como revolução verde, desvinculando progressivamente o conceito de rural do de agrícola e 0 de desenvolvimento rural do de modernização agrícola (DELGADO, 2009. p.4).

Antes deste processo, especialmente na década de 1970, a concepção de rural era sinônimo de agrícola e o desenvolvimento rural equivalia à modernização da agricultura, fortemente subvencionada pelo Estado. Não obstante, também era

Estudos Geográficos, Rio Claro, 17: 116-133, jan./jun. 2019 (ISSN 1678-698X) http://www.periodicos.rc.biblioteca.unesp.br/index.php/estgeo 
sua característica as intervenções de organismos internacionais nas regiões rurais que não tinham se adaptado aos padrões considerados modernos de tecnologia produtiva e que não contribuíam com a economia através da indústria, do comércio e dos serviços. Por padrões modernos de tecnologia entende-se a mecanização da produção (DELGADO, 2009; SCHNEIDER, 2010), "[...] produzindo transformações socioeconômicas no meio rural que trouxeram resultados bastante penosos para os trabalhadores rurais e muito favoráveis às elites agrárias, agrícolas e agroindustriais" (DELGADO, 2009. p. 4).

\section{DESENVOLVIMENTO RURAL NA PERSPECTIVA DO SOCIAL-REDISTRIBUTIVISMO}

$\mathrm{Na}$ década de 1990 o Brasil convive com dois projetos políticos contraditórios de desenvolvimento rural. O primeiro foi o neoliberal, defendido pelas elites políticas e econômicas, tendo como baluarte o agronegócio, que retoma a perspectiva de que o papel da agricultura na economia é garantir equilíbrio na balança comercial do País com as exportações. Por outro lado, o projeto democratizante do trabalho no espaço rural era o seu contraponto, que tinha inicialmente como base a reforma agrária e o foco na agricultura familiar, mas que incorpora, posteriormente, novas propostas. Este projeto pautou-se pela valorização da agricultura de mercado interno, pelo reconhecimento dos direitos sociais das populações rurais, pela democratização do acesso às políticas públicas e pelo objetivo fundamental da segurança alimentar e nutricional da população brasileira. Neste caso, os protagonistas foram os "sem terra", "os assentados" e os "agricultores familiares".

Segundo Delgado (2009), esse protagonismo se deu em virtude da intensidade e da abrangência das tensões e das lutas sociais que travaram, da evolução em relação à crítica ao modelo neoliberal, tanto intelectual quanto política, além do fato de que reconheceram que era necessário, para ter atendidas as demandas dos seus representados, disputar os recursos públicos administrados pelo Estado através de políticas públicas. Além do mais, entenderam a importância de se ter voz, buscando participar assim da construção institucional de um novo modelo de desenvolvimento rural alternativo (DELGADO, 2009).

Como consequência desse movimento, o projeto democratizante desconstruiu intelectual e politicamente a concepção de rural como agrícola e de desenvolvimento como modernização, e continua buscando reconstruir, intelectual e politicamente, conteúdos mais adequados, ao avanço do projeto, para as noções de rural e de desenvolvimento rural, numa trajetória difícil e complexa e ainda não concluída, apesar de todos os avanços feitos (DELGADO, 2009, p. $5)$.

A partir de 2003, com a chegada ao governo de um projeto democráticopopular, houve o fortalecimento do projeto social-redistributivista, sem que, contudo, houvesse um total rompimento com o projeto neoliberal. O governo Lula montou um aparato governamental mais consistente e abrangente de apoio à agricultura familiar e a outras populações e povos habitantes do meio rural, criando o Ministério do Desenvolvimento Agrário voltado exclusivamente para as questões e temas relativos ao fortalecimento e à consolidação da agricultura familiar no país, bem como ao

Estudos Geográficos, Rio Claro, 17: 116-133, jan./jun. 2019 (ISSN 1678-698X) http://www.periodicos.rc.biblioteca.unesp.br/index.php/estgeo 
reconhecimento do direito ao acesso a políticas públicas e à reprodução econômica e social sustentável da diversidade de populações e povos existentes no meio rural. Nessa perspectiva, o rural foi apreendido como um espaço múltiplo e diverso.

Quanto às políticas de desenvolvimento rural voltadas para este público, destacam-se: a nacionalização e ampliação dos recursos e inclusão de outros segmentos mais pauperizados da agricultura familiar no programa nacional de fortalecimento da agricultura familiar (PRONAF); o Plano Safra para a agricultura familiar; a política nacional de reestruturação do programa de assistência técnica e de extensão rural para os agricultores familiares, quilombolas, assentados, pescadores artesanais, povos indígenas; o programa de aquisição de alimentos (PAA); a recriação do Conselho de Segurança Alimentar (CONSEA); a mudança do nome do Conselho Nacional de Desenvolvimento Rural Sustentável para CONDRAF, para ressaltar a reforma agrária e a agricultura familiar; e, por fim, a instituição do Programa Territórios da Cidadania.

\section{O PROGRAMA TERRITÓRIOS DA CIDADANIA}

O Programa Territórios da Cidadania - PTC foi implantado em 2008, já no segundo mandato do presidente Lula, inspirado no Programa de Desenvolvimento Sustentável de Territórios Rurais (PDSTR), que vinha sendo desenvolvido sob a coordenação do Ministério do Desenvolvimento Agrário (MDA). Intencionou-se com o PTC ampliar as ações de atuação e o número de ministérios envolvidos como uma estratégia de desenvolvimento rural sustentável para as regiões do país com menores índices de desenvolvimento social e econômico, objetivando proporcionar o desenvolvimento econômico e a universalização dos programas básicos de cidadania (BRASIL, 2008).

Os Territórios da Cidadania são os recortes espaciais de referência para a mobilização da população e a implementação das ações. Estipulou-se como área, em regra, espaços maiores que um determinado município e menores que o estado federado. Para Raffestin (2009, p. 26), há uma distinção de espaço e território, sendo este último "gerado a partir do espaço, construindo o resultado de uma ação conduzida por um ator que realiza um programa em qualquer nível. Apropriando-se concretamente ou abstratamente (por exemplo, através da representação) de um espaço, o ator o 'territorializa'”.

Os critérios que deveriam ser ponderados para a escolha e priorização do território a ser incorporado ao Programa incluíam o menor Índice de Desenvolvimento Humano - IDH; a maior concentração de beneficiários do Programa Bolsa Família; a maior concentração de agricultores familiares e assentados da reforma agrária; a maior concentração de populações tradicionais, quilombolas e indígenas; o baixo dinamismo econômico, segundo a tipologia das desigualdades regionais constantes da Política Nacional de Desenvolvimento Regional - PNDR, do Ministério da Integração Nacional; a convergência de programas de apoio ao desenvolvimento de distintos níveis de governo; a maior organização social; e a maior concentração de municípios de menor Índice de Desenvolvimento de Educação Básica - IDEB.

O governo federal, através da escolha desses critérios, delimitou as unidades territoriais beneficiárias do Programa e adotou intencionalmente, como escala mediadora da ação, a articulação entre as esferas administrativas federal, estadual e municipal e a aproximação com as organizações sociais territoriais.

Estudos Geográficos, Rio Claro, 17: 116-133, jan./jun. 2019 (ISSN 1678-698X) http://www.periodicos.rc.biblioteca.unesp.br/index.php/estgeo 
O grau de importância que assumiram, efetivamente, os critérios de definição dos recortes territoriais e fundamentaram a elegibilidade dos municípios na composição dos Territórios foram estudados por Andrade, Strauch e Ferreira (2016), que concluíram que critérios como a concentração de agricultores familiares; o baixo índice de desenvolvimento da educação básica da rede pública - IDEB e o baixo índice de desenvolvimento humano - IDH se mostraram relevantes, sendo que este último apresentou-se como o principal. No entanto, critérios como a densidade demográfica e a existência de comunidades quilombolas e população indígena não tiveram o protagonismo esperado.

A gestão do Programa foi concebida para se dar em quatro instâncias: 1) o Comitê Gestor Nacional; 2) o Grupo Interministerial (23 ministérios) de Execução e Acompanhamento - GIEA (Gestão federal); 3) os Comitês de Articulação Estadual (Articulação Federativa); e 4) os Colegiados Territoriais (espaço de expressão de poder composto por instituições da sociedade civil representantes dos diversos segmentos da agricultura familiar e da reforma agrária e de representações das três esferas do poder público presentes no território), instituídos por meio de decreto presidencial no momento de sua criação.

No Decreto que o instituiu foram definidos como objetivos promover e acelerar a superação da pobreza e das desigualdades sociais no meio rural, inclusive as de gênero, raça e etnia, por meio de estratégia de desenvolvimento territorial sustentável, contemplando: a integração de políticas com base no planejamento territorial; a ampliação dos mecanismos de participação social na gestão das políticas públicas de interesse do desenvolvimento dos territórios; a ampliação da oferta dos programas básicos de cidadania; a inclusão e integração produtiva das populações pobres e dos segmentos sociais mais vulneráveis, tais como trabalhadoras rurais, quilombolas, indígenas e populações tradicionais; a valorização da diversidade social, cultural, econômica, política, institucional e ambiental das regiões e populações.

Apesar de todo o potencial que tem o mundo rural, segundo Buarque (2012), utilizando dados do Censo de 2010, ele tem a maior densidade de extremamente pobres (25,5\% da sua população) no total da população brasileira. Além disso, a sua distribuição no espaço geográfico brasileiro é desigual, formando manchas de concentração (principalmente nas regiões norte e nordeste). $\mathrm{O}$ autor atribui ainda 0 adensamento territorial da pobreza às deficiências socioeconômicas, ambientais e culturais do território onde habitam e não a uma intenção voluntária de os pobres se juntarem em determinados espaços. Relaciona a distribuição da pobreza no território às condições sistêmicas dele, fatores exógenos e macros que definem as circunstâncias para a geração de riqueza e sua distribuição na sociedade.

Ele ressalta que a pobreza é um fenômeno de múltiplas dimensões que pode ser qualificada e diferenciada em dois aspectos diferentes e complementares, "a multiplicidade das carências" (de renda, serviços sociais como água, energia, saneamento, hospitais, etc.) e a "multiplicidade de causas determinantes" (econômicas, culturais, tecnológicas e naturais).

O ciclo de implementação do PTC inicia-se pela elaboração de uma Matriz de Ações anual, contendo as ações ofertadas pelo Governo Federal (18 ministérios) aos Territórios, com dados descritivos, metas e valores territorializados.

Em seguida, o Comitê de Articulação Estadual realiza e coordena o debate territorial, momento em que a Matriz é apresentada em cada Território e o Colegiado indica demandas e prioridades. Dessa discussão resulta o Plano de Execução dos ministérios ofertantes de ações, cujo controle foi previsto pelo acompanhamento do

Estudos Geográficos, Rio Claro, 17: 116-133, jan./jun. 2019 (ISSN 1678-698X) http://www.periodicos.rc.biblioteca.unesp.br/index.php/estgeo 
Relatório de Execução que apresenta detalhes do estágio da execução física e orçamentário-financeiro, as restrições, os riscos e as providências adotadas.

A execução das ações foi organizada a partir de três grandes eixos estruturantes de atuação relacionadas: i) às atividades produtivas: ii) à implantação e melhoramento de infraestruturas; e iii) ao reconhecimento de cidadania, acesso e ampliação de direitos. Os eixos se desdobram em sete grupos temáticos de ações, sendo eles: produção; desenvolvimento social; saúde; educação; capacitações; infraestrutura e ações fundiárias.

\section{O PTC NOS TERRITÓRIOS BICO DO PAPAGAIO, SUDESTE E JALAPÃO, NO ESTADO DO TOCANTINS}

O arranjo territorial Territórios da Cidadania no estado do Tocantins fez poucas alterações, ou nenhuma, à microrregionalização adotada pelo IBGE. O TC Bico do Papagaio tem os mesmos 25 municípios da microrregião Bico do Papagaio; o TC Sudeste tem 19 dos 20 municípios da microrregião Dianópolis (não incluiu o município de Santa Rosa do Tocantins) e agregou mais 2 (São Salvador do Tocantins e Palmeirópolis) da microrregião de Gurupi; o TC Jalapão agrupou 8 municípios dos 15 da microrregião Jalapão.

O TC Bico do Papagaio encontra-se no extremo norte do estado do Tocantins foi o primeiro a ser instituído em 2008. O TC Jalapão está a leste e o TC Sudeste, no sudeste do estado, ambos foram institucionalizados no ano de 2009. As regiões em que se encontram os três Territórios, ficaram isoladas do maior corredor logístico e propulsor de desenvolvimento econômico do estado que é a BR-153 (mapa 02).

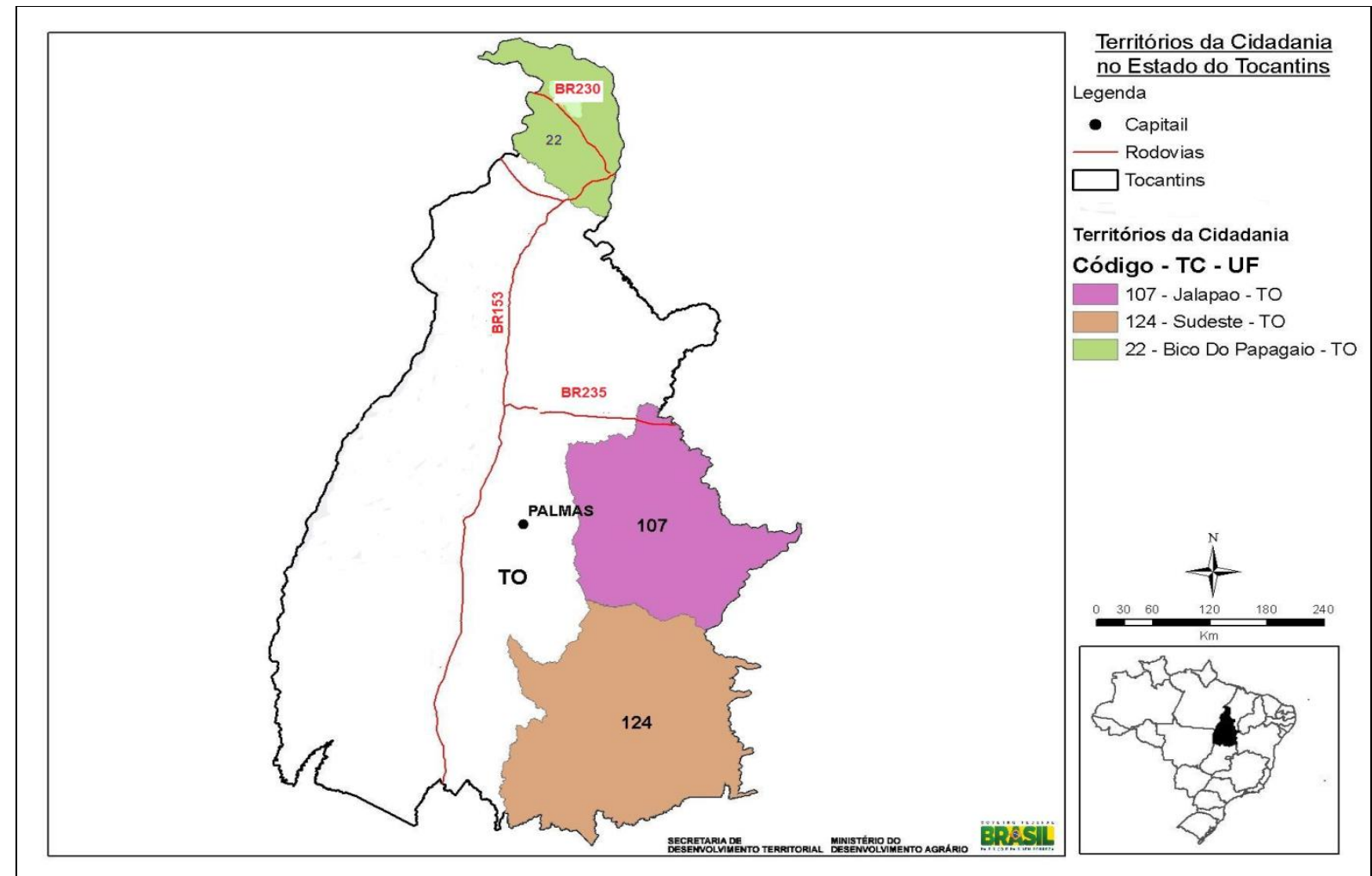

Mapa 01 - Territórios da Cidadania no estado do Tocantins

Fonte: Sistema de informações territoriais/MDA

Estudos Geográficos, Rio Claro, 17: 116-133, jan./jun. 2019 (ISSN 1678-698X) http://www.periodicos.rc.biblioteca.unesp.br/index.php/estgeo 
Os três TC têm características que se enquadram nos critérios definidos pelo Programa: IDHM baixo, concentração de agricultura familiar, presença de comunidades quilombolas, assentamentos da reforma agrária, indígenas, extrativistas e pescadores. Essas regiões também concentram maior número de pessoas pobres e extremamente pobres do estado do TO.

Mesmo com essas características em comum, eles também guardam especificidades entre si, tais como: o TC Jalapão possui a menor quantidade de municípios (08), tem um ecossistema singular e belezas naturais diversificadas (fervedouros, cachoeiras, dunas) que implicaram na institucionalização de unidades de conservação (UC) ambientais (é o TC com a menor densidade populacional 0,89 hab./Km²); o TC Sudeste tem a maior taxa de urbanização dos três Territórios, possui um patrimônio histórico e cultural edificado, tem clima mais ameno e é a região serrana do estado; o TC Bico do Papagaio tem o maior número de municípios (25), mas é o menor em extensão territorial $\left(15.767,97 \mathrm{Km}^{2}\right)$, tem a maior densidade populacional - 12,45 hab/ $/ \mathrm{km}^{2}$ dos três Territórios e é o TC que possui mais assentamentos da reforma agrária (108 no total).

\section{O TERRITÓRIO DA CIDADANIA SUDESTE}

O Território da Cidadania Sudeste foi instituído em 2009 por decreto presidencial, com uma área de $48.510 .72 \mathrm{Km}^{2}$ e composto por 21 municípios: Almas, Arraias, Aurora do Tocantins, Chapada da Natividade, Combinado, Conceição do Tocantins, Dianópolis, Lavandeira, Natividade, Novo Alegre, Novo Jardim, Palmeirópolis, Paranã, Pindorama do Tocantins, Ponte Alta do Bom Jesus, Porto Alegre do Tocantins, Rio da Conceição, São Salvador do Tocantins, São Valério, Taguatinga e Taipas do Tocantins. O IDH médio do Território, em 2010, era de 0,67, ou seja, médio desenvolvimento.

Segundo o censo demográfico do IBGE (2010), esse Território tinha em 2010 uma população de 123.791 pessoas, sendo que $71,66 \%$ moravam na área urbana. Dentre os municípios que compõem o Território, apenas 01 tinha população rural maior que a urbana, o município de Paranã. A desigualdade de número de habitantes por município é grande, existindo município com população total (urbana e rural) de 1.605 habitantes e município com 19.112 habitantes.

Podemos dizer que o Território Sudeste é uma das manchas de pobreza no território brasileiro. Em 2010, dos 21 municípios, apenas quatro (Combinado, Dianópolis, Palmeirópolis e Novo Alegre) tinham menos de 10\% da população em situação de extrema pobreza e, mais grave ainda, é que todos tinham mais de $50 \%$ da população vulnerável à pobreza.

Estudos Geográficos, Rio Claro, 17: 116-133, jan./jun. $2019 \quad$ (ISSN 1678-698X) http://www.periodicos.rc.biblioteca.unesp.br/index.php/estgeo 


\section{Quadro 1 - \% da população extremamente pobre e \% vulnerável à pobreza por município, no TC Sudeste}

\begin{tabular}{|c|c|c|}
\hline MUNICÍPIO & $\begin{array}{c}\% \\
\text { EXTREMAMENTE } \\
\text { POBRES(2010) }\end{array}$ & $\begin{array}{c}\text { \% } \\
\text { VULNERÁVEIS } \\
\text { À } \\
\text { POBREZA(2010) }\end{array}$ \\
\hline Almas & 15.32 & 73.83 \\
\hline Arraias & 18.32 & 72.07 \\
\hline Aurora do Tocantins & 13.37 & 81.48 \\
\hline Chapada da Natividade & 26.85 & 87.70 \\
\hline Combinado & 4.18 & 74.32 \\
\hline Conceição do Tocantins & 17.94 & 81.89 \\
\hline Dianópolis & 8.03 & 85.48 \\
\hline Lavandeira & 15.60 & 59.89 \\
\hline Natividade & 14.74 & 78.19 \\
\hline Novo Alegre & 8,86 & 84.50 \\
\hline Novo Jardim & 17.14 & 74.55 \\
\hline Palmeirópolis & 7.71 & 86.49 \\
\hline Paranã & 31.89 & 55.17 \\
\hline Pindorama do Tocantins & 23.32 & 79.93 \\
\hline Ponte Alta do Bom Jesus & 31.17 & 70.35 \\
\hline Porto Alegre do Tocantins & 17.42 & 80.81 \\
\hline Rio da Conceição & 26.41 & 91.40 \\
\hline São Salvador do Tocantins & 28.22 & 89.25 \\
\hline São Valério & 17.20 & 88.92 \\
\hline Taguatinga & 21.96 & 70.18 \\
\hline Taipas do Tocantins & 17.08 & 73.59 \\
\hline
\end{tabular}

Fonte: Censo demográfico/IBGE (2010).

O IDHM de todos os municípios aumentou entre 2000 e 2010. Em 2000 eram 17 municípios com IDHM classificado como "muito baixo desenvolvimento humano" (de 0,000 a 0,599). Em 2010, apenas três municípios permaneceram nesse estrato. Quanto à concentração de renda, entre 2000 e 2010, onze (11) municípios diminuíram seu índice de Gini, porém o Território permaneceu bastante concentrador. Apenas 01 município tem índice menor que 0,5.

Neste Território, do final da década de 1980 até início da segunda dos anos 2000, foram criados 23 assentamentos da reforma agrária e assentadas 879 famílias, numa área reformada de 60.206,83ha. Os três primeiros assentamentos da reforma agrária surgiram nos municípios de São Valério da Natividade (1987) e em Chapada da Natividade (1988 e 1989). Os outros 20 foram criados nas décadas de 1990 e de 2000 (8 e 12, respectivamente).

O município de São Valério é o que possui o maior número de assentamentos (5), a maior área reformada (14.209,94 ha) e o maior número de famílias assentadas (233) e o município de Paranã possui a menor quantidade de famílias assentadas (24) e a menor área reformada (1.321,7263 ha).

Apesar da política de reforma agrária - dos anos de 1980 até o início da segunda década dos anos 2000 - ter criado 23 assentamentos, a estrutura fundiária do Território Sudeste é fortemente concentrada. Há o predomínio dos Estudos Geográficos, Rio Claro, 17: 116-133, jan./jun. 2019 (ISSN 1678-698X) http://www.periodicos.rc.biblioteca.unesp.br/index.php/estgeo 
estabelecimentos entre 10 e 100 ha, correspondendo a 47,19\% do total dos estabelecimentos, os quais ocupam somente $6,85 \%$ da área total do Território, que é de 48. 510,72 $\mathrm{Km}^{2}$. Em relação à área predominam os estabelecimentos acima de 2.500 ha, os quais representam $38,46 \%$ da área total e apenas $2,42 \%$ do número total de estabelecimentos (PTDRS, 2011).

Abaixo, apresentamos um quadro resumo das características do Território.

\section{Quadro 2 - Resumo das características do Território Sudeste}

\begin{tabular}{|l|r|}
\hline \multicolumn{1}{|c|}{ VARIÁVEL } & \multicolumn{1}{|c|}{ VALOR } \\
\hline Área(em Km²) & 48.510 .72 \\
\hline População Total (hab.) & $123.791(2010)$ \\
\hline População Urbana (hab.) & $88.703(2010)$ \\
\hline População Rural (hab.) & 35.088 \\
\hline $\mathrm{N}^{\circ}$ de Famílias Assentadas - Reforma Agrária & 879 \\
\hline Número de Projetos - Reforma Agrária & 23 \\
\hline Área Reformada - Reforma Agrária (em hectares) & $60.206,83$ \\
\hline $\mathrm{N}^{\circ}$ de estabelecimentos da agricultura familiar & 6.376 \\
\hline Pessoal ocupado na agricultura familiar & 18.687 \\
\hline Número de Pescadores & 153 \\
\hline IDH médio & 0,67 \\
\hline Comunidades Quilombolas & 08 \\
\hline
\end{tabular}

Fonte: SIT/MDA-2015 com base em dados do IBGE, Censo Demográfico (2010); INCRA (2014); Atlas do Desenvolvimento Humano (2014); Índice de Desenvolvimento Humano/PNUD (2014), PTDRS (2011). FCP (2015)

\section{TERRITÓRIO DA CIDADANIA BICO DO PAPAGAIO}

O TC Bico do Papagaio foi o primeiro Território a ser institucionalizado no estado do Tocantins, em 2008, ano em que o PTC foi lançado no Brasil em 60 Territórios. Ele é composto por 25 municípios: Aguiarnópolis, Ananás, Angico, Araguatins, Augustinópolis, Axixá do Tocantins, Buriti do Tocantins, Cachoeirinha, Carrasco Bonito, Darcinópolis, Esperantina, Itaguatins, Luzinópolis, Maurilândia do Tocantins, Nazaré, Palmeiras do Tocantins, Praia Norte, Riachinho, Sampaio, Santa Terezinha do Tocantins, São Bento do Tocantins, São Miguel do Tocantins, São Sebastião do Tocantins, Sítio Novo do Tocantins e Tocantinópolis.

Segundo o Censo Demográfico do IBGE (2010), esse Território tinha em 2010 uma população de 196.367 pessoas, sendo que 66,13\% moravam na área urbana. Dentre os municípios que compõem o Território, 02 tinham população rural maior que a urbana, os municípios de Nazaré e de São Miguel do Tocantins, com destaque para este último que tinha $75,70 \%$ da sua população morando na área rural. A desigualdade de número de habitantes por município é grande, existindo município com população total (urbana e rural) com uma centena a mais de 2000 habitantes (Cachoeirinha, Luzinópolis, Santa Terezinha do Tocantins) e outros com mais de 20 mil habitantes (Tocantinópolis, Araguatins).

Segundo a Fundação Cultural Palmares, entre 2010 e 2014, quatro (04) comunidades quilombolas foram certificadas: uma em Araguatins e três em Esperantina. Há nesse Território a reserva indígena Apinajé nos municípios de Tocantinópolis, São Bento do Tocantins, Cachoeirinha e Maurilândia.

Estudos Geográficos, Rio Claro, 17: 116-133, jan./jun. 2019 (ISSN 1678-698X) http://www.periodicos.rc.biblioteca.unesp.br/index.php/estgeo 
Os percentuais de pessoas em extrema pobreza nos municípios no Território Bico do Papagaio em 2010 são de, aproximadamente, 7\% (Ananás e Aguiarnópolis) há municípios com mais de 30\% (Sítio Novo do Tocantins, Riachinho, Esperantina). Já o percentual de pessoas vulneráveis à pobreza é extremamente alto, tendo municípios com mais de $90 \%$ ( Maurilândia do TO e São Bento do TO). Ananás é o município com o menor percentual de extremamente pobres $(6,81)$ e de vulneráveis à pobreza $(45,67)$.

\section{Quadro 3 - \% da população extremamente pobre e \% vulnerável à pobreza por município, no TC Bico do Papagaio}

\begin{tabular}{|l|c|c|}
\hline \multicolumn{1}{|c|}{ MUNICÍPIO } & $\begin{array}{c}\text { \% } \\
\text { EXTREMAMENTE } \\
\text { POBRES(2010) }\end{array}$ & $\begin{array}{c}\text { \% VULNERÁ VEIS } \\
\text { À POBREZA } \\
\mathbf{( 2 0 1 0 )}\end{array}$ \\
\hline Aguiarnópolis & 6.95 & 78.79 \\
\hline Ananás & 6.81 & 45.67 \\
\hline Angico & 13.51 & 78.38 \\
\hline Araguatins & 19.69 & 85.30 \\
\hline Augustinópolis & 9.01 & 77.59 \\
\hline Axixá do Tocantins & 16.48 & 81.50 \\
\hline Buriti do Tocantins & 19.26 & 77.24 \\
\hline Cachoeirinha & 18.58 & 85.20 \\
\hline Carrasco Bonito & 28.14 & 80.65 \\
\hline Darcinópolis & 13.50 & 70.19 \\
\hline Esperantina & 36.37 & 74.31 \\
\hline Itaguatins & 23.75 & 79.90 \\
\hline Luzinópolis & 13.76 & 86.30 \\
\hline Maurilândia do Tocantins & 25.93 & 92.86 \\
\hline Nazaré & 17.81 & 72.29 \\
\hline Palmeiras do Tocantins & 16.74 & 87.45 \\
\hline Praia Norte & 27.91 & 61.97 \\
\hline Riachinho & 35.04 & 87.60 \\
\hline Sampaio & 21.21 & 87.56 \\
\hline Santa Terezinha do Tocantins & 20.63 & 83.10 \\
\hline São Bento do Tocantins & 18.20 & 91.50 \\
\hline São Miguel do Tocantins & 18.32 & 86.49 \\
\hline São Sebastião do Tocantins & 29.96 & 84.84 \\
\hline Sítio Novo do Tocantins & 32.02 & 67.28 \\
\hline Tocantinópolis & 10.17 & \\
\hline Font Censodemogá & & \\
\hline
\end{tabular}

Fonte: Censo demográfico/IBGE (2010).

Em 2000, apenas 01 município (Tocantinópolis) tinha IDHM classificado como "baixo", os outros 24 municípios tinham ios aumentou: 18 municípios passaram a ter IDHM "médio" (0,600 a 0,699), sete municípios, apesar de terem aumentado seu IDHM, só atingiram o estrato de "baixo desenvolvimento humano".

Quanto à concentração de renda, entre 2000 e 2010, houve uma diminuição da concentração de renda em 21 municípios, porém o Território permanece

Estudos Geográficos, Rio Claro, 17: 116-133, jan./jun. $2019 \quad$ (ISSN 1678-698X) http://www.periodicos.rc.biblioteca.unesp.br/index.php/estgeo 
concentrador de renda. Apenas 04 municípios têm índice menor que 0,5 (Aguiarnópolis, Ananás, Angico, Cachoeirinha e Luzinópolis).

Do final da década de 1980 até início da segunda dos anos 2000, foram criados 108 assentamentos da reforma agrária e assentadas 6.026 famílias, numa área reformada de 243.323,717ha, apenas 02 municípios do Território, não têm assentamentos (Santa Terezinha do Tocantins e Nazaré). Entre 1987 e 1989 foram criados 15 assentamentos na região. Período de acirrados conflitos pela posse da terra, pois a grilagem, a expropriação violenta das famílias, as perseguições e assassinatos dos posseiros foram práticas correntes. Os primeiros assentamentos foram criados em 1987 nos municípios de Axixá, Praia Norte e Sítio Novo. O município de Araguatins é o que possui o maior número de assentamentos (21), maior quantidade de famílias assentadas (1.402) e a maior área reformada (51.887,11ha).

\section{O TERRITÓRIO DA CIDADANIA JALAPÃO}

O Território da Cidadania Jalapão foi instituído no segundo ano do Programa, em 2009, com uma área de $32.284,80 \mathrm{Km}^{2}$ e composto por 08 municípios: Lagoa do Tocantins, Lizarda, Mateiros, Novo Acordo, Ponte Alta do Tocantins, Rio Sono, Santa Tereza do Tocantins e São Félix do Tocantins. O IDH médio do Território é 0,607.

Segundo o Censo Demográfico do IBGE (2010), esse Território tinha em 2010 uma população de 30.629 pessoas, sendo que $62,37 \%$ moravam na área urbana. Dentre os municípios que compõem o Território, apenas 01 tinha população rural maior que a urbana, o município de Rio Sono. Apenas dois municípios tinham população total, em 2010, entre 6.000 e 7.000 habitantes (Rio Sono e Ponte Alta do Tocantins). A densidade demográfica no Território é de apenas 0,89 hab./Km².

Com relação aos percentuais de pessoas em extrema pobreza e em vulnerabilidade à pobreza nos municípios desse território, podemos dizer que o Jalapão é extremamente pobre. Em 2010, dos 08 municípios, apenas 01 (Santa Tereza do Tocantins) tinha menos de $10 \%$ da população em situação de extrema pobreza; 02 municípios com \% na casa dos 30; um (01) na casa dos $20 \%$; e 01 bem próximo da metade da população $(48,36 \%)$. Mais grave ainda, é que todos tinham mais de $70 \%$ da população vulnerável à pobreza, dentre eles, 01 tinha $91,36 \%$ da população vulnerável à pobreza.

\section{Quadro 4 - \% da população extremamente pobre e \% vulnerável à pobreza por município, no TC Jalapão}

\begin{tabular}{|ccc|} 
MUNICíPIO & $\begin{array}{c}\text { \% EXTREMAMAENTE } \\
\text { POBRES(2010) }\end{array}$ & $\begin{array}{c}\text { \% VULNERÁ VEIS À } \\
\text { POBREZA (2010) }\end{array}$ \\
Lagoa do Tocantins & 33,42 & 70,38 \\
Lizarda & 48,36 & 91,36 \\
Mateiros & 15,96 & 70,72 \\
Novo Acordo & 18,21 & 72,95 \\
Ponte Alta do Tocantins & 19,53 & 77,08 \\
Rio Sono & 27,2 & 76,07 \\
Santa Tereza do Tocantins & 7,81 & 86,46 \\
São Félix do Tocantins & 36,15 & 83,83 \\
\hline
\end{tabular}

Estudos Geográficos, Rio Claro, 17: 116-133, jan./jun. 2019 (ISSN 1678-698X) http://www.periodicos.rc.biblioteca.unesp.br/index.php/estgeo 
O IDHM de todos os municípios aumentou entre 2000 e 2010. Em 2010, cinco municípios passaram de "muito baixo desenvolvimento humano" (de 0,000 a $0,599)$ para o estrato de "médio desenvolvimento" $(0,600$ a 0,699) e três municípios (Lizarda, Lagoa do Tocantins e São Félix do Tocantins) passaram para "baixo desenvolvimento" $(0,500$ a 0,599$)$.

Quanto à concentração de renda, entre 2000 e 2010, sete (07) municípios diminuíram a concentração de renda e 01 município (Lizarda) concentrou mais ainda a renda 0,71. Dessa forma, o Território permaneceu concentrador. Apenas 01 município (São Félix do Tocantins) tem índice menor que 0,5.

Segundo o Relatório de Assentamentos do INCRA (2017), neste Território, do final da década de 1980 até início da segunda dos anos 2000, foram criados 04 assentamentos da reforma agrária e assentadas 186 famílias, numa área reformada de 9.367,98ha. Os dois primeiros assentamentos da reforma agrária surgiram nos municípios de Novo Acordo e em Rio Sono, no ano de 1998.

\section{DISTRIBUIÇÃO DAS AÇÕES POR TEMAS EM CADA UM DOS TRÊS TERRITÓRIOS DA CIDADANIA}

As ações/programas ofertados aos Territórios e os implementados não foram os mesmos no período de 2008 a 2014. Segundo o MDA, em resposta dada aos autores deste artigo por e-mail, sobre as matrizes de ação e relatórios de execução dos anos de 2011 e 2012,

no período de 2011 a 2012 o Programa foi rediscutido, a partir da implementação do Plano Brasil Sem Miséria e do novo Plano Plurianual (PPA), e ajustado para alinhar a Matriz de Ações aos novos programas de governo, no entanto, as ações não deixaram de ser implementadas nos Territórios, apenas não foram apresentadas na forma de uma matriz de ações.

Diante disso, trabalhamos com os dados dos Relatórios de Execução dos anos 2008, 2009, 2013 e 2014, por não existirem os referentes aos anos de 2011 e 2012.

O PTC articulou as políticas e programas (ações) em 07 temas (infraestrutura; ações fundiárias; apoio à gestão territorial; organização sustentável da produção; saúde, saneamento e acesso à água; educação e cultura; direitos e desenvolvimento social).

Ao analisarmos os gráficos seguintes, podemos constatar os temas que foram priorizados por cada um dos Territórios anualmente, para o período de 2008 a 2010 e 2013 e 2014.

Estudos Geográficos, Rio Claro, 17: 116-133, jan./jun. 2019 (ISSN 1678-698X) http://www.periodicos.rc.biblioteca.unesp.br/index.php/estgeo 


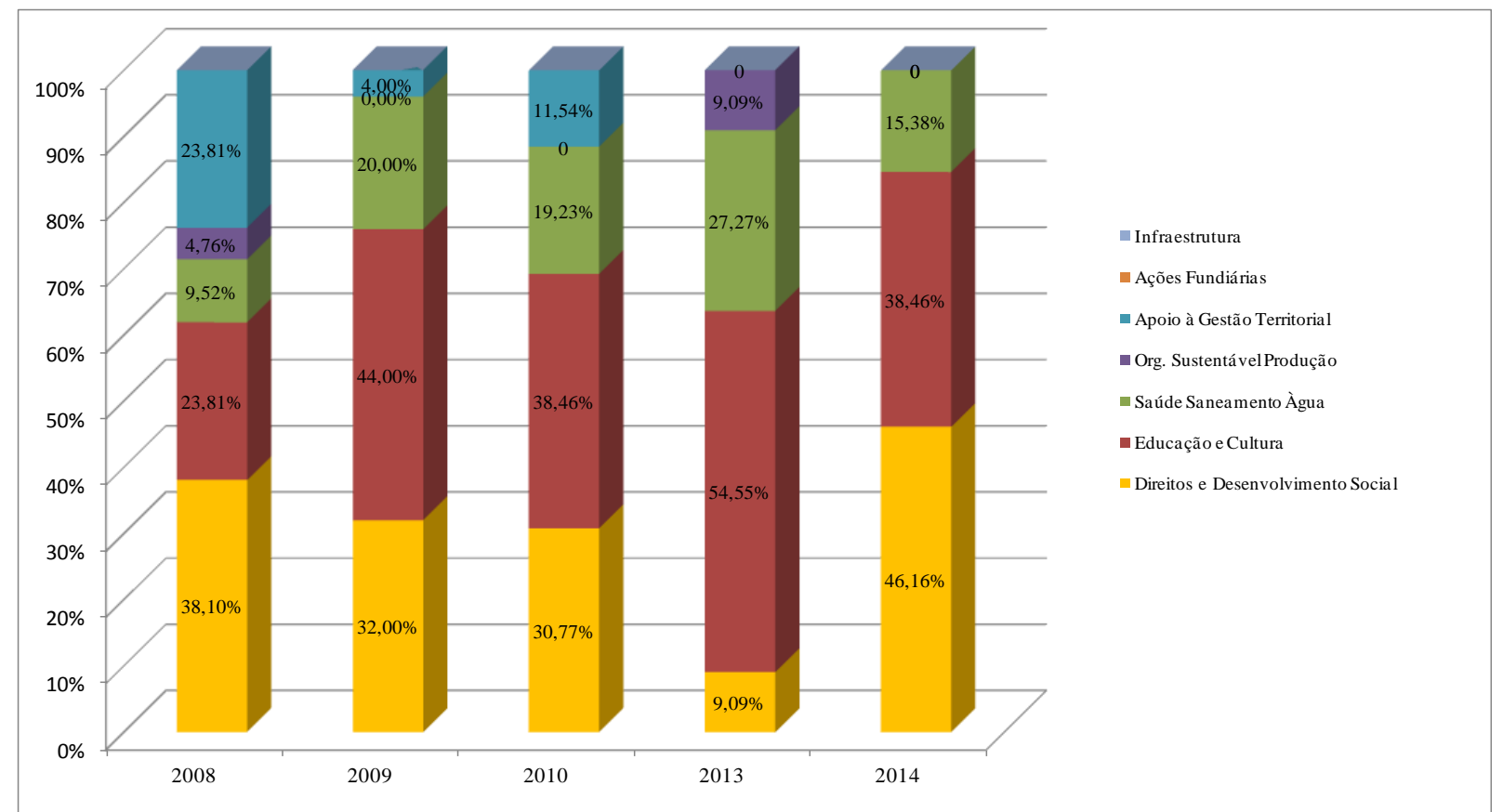

Gráfico 1 - Participação dos temas por número de ações por ano (2008 a 2014) no TC Bico do Papagaio

Fonte: Relatório de Execução 2008, 2009, 2010, 2013, 2014.

Conforme nos mostra o gráfico 1 , os temas mais priorizados em participação no período todo foram direitos e desenvolvimento social; educação e cultura; saúde, saneamento e acesso à água. No ano de implantação (2008) do Programa, nesse Território, foram articuladas ações/programas em cinco dos sete temas. Com destaque para o tema direitos e desenvolvimento social, que teve o maior número de ações/programas implementados, seguido dos temas educação e cultura e; apoio à gestão territorial. Este último, tem uma priorização decrescente durante a implementação do Programa - em número de ações e na participação da composição do planejamento de cada ano - dessa forma, compõe a articulação de ações nos anos de 2008, 2009 e 2010 e deixa de compor nos anos seguintes.

O tema educação e cultura foi o que se manteve mais estável durante todos os anos (participando com um percentual nunca inferior a $23 \%$ das ações implementadas em cada ano); o tema saúde, saneamento e acesso à água compôs a matriz de ações de todos os anos, ora participando com 9,52\% das ações (no ano de 2008), ora com 27, 27\% das ações (no ano de 2013).

O tema organização sustentável da produção foi priorizado, ascendentemente, em dois anos (2008 e 2013), dos cinco.

Analisando o gráfico, é possível ordenar as prioridades para exercício de cidadania, assim: educação e cultura; direitos e desenvolvimento social; saúde, saneamento e acesso à água; gestão territorial e organização sustentável da produção.

Estudos Geográficos, Rio Claro, 17: 116-133, jan./jun. 2019 (ISSN 1678-698X) http://www.periodicos.rc.biblioteca.unesp.br/index.php/estgeo 


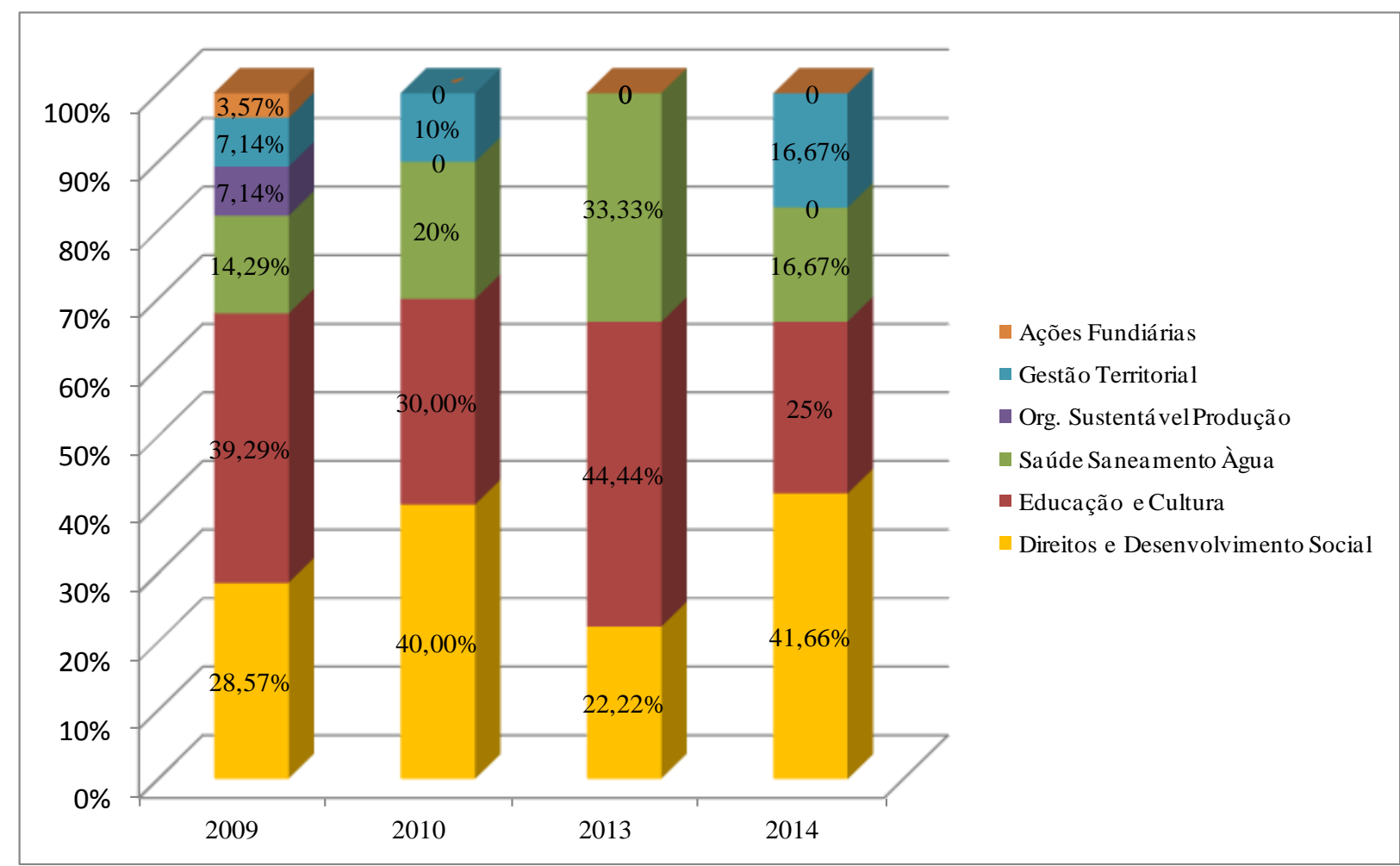

Gráfico 2 - Participação dos temas por número de ações por ano (2009 a 2014) no TC Jalapão

Fonte: Relatório de Execução 2009, 2010, 2013 e 2014.

No eixo "cidadania e direitos" o número de ações por tema variou ano a ano. Do total de 69 ações/políticas implementadas no período de 2009, 2010, 2013 e 2014 no TC Jalapão (Quadro 15), os temas que contribuíram com mais ações/políticas e em todos os anos foram "educação e cultura"; "direitos e desenvolvimento social" e "saúde, saneamento e acesso à água".

De acordo com o gráfico 32, no primeiro ano (2009) do Programa nesse Território, a articulação de políticas se deu contemplando seis dos sete temas (educação e cultura; direitos e desenvolvimento social; apoio à gestão territorial; organização sustentável da produção; ações fundiárias; saúde, saneamento e acesso à água). Preponderando as ações relacionadas ao tema educação e cultura, seguido do tema direitos e desenvolvimento social.

No segundo ano, em 2010, cresce o número de ações do tema direitos e cidadania, assim como crescem também os programas/ações do tema saúde, saneamento e acesso à água e; do tema gestão fundiária. $\mathrm{O}$ tema educação e cultura tem uma pequena diminuição de ações nesse ano.

No quinto ano (2013) do Programa no TC Jalapão, o tema saúde, saneamento e acesso à água participa com o seu maior número de ações durante todo o período. Nesse ano, todas as ações implementadas são provenientes dos temas educação e cultura; direitos e desenvolvimento social e; saúde, saneamento e acesso à água.

Em 2014, o tema apoio à gestão territorial volta a ter ações priorizadas e participa com o mesmo número de programas/ações que o tema saúde, saneamento e acesso à água. Nesse ano o tema direitos e desenvolvimento social é o que participa com o maior número de ações.

Percebe-se que, por ordem de priorização dos temas eles estão assim: num mesmo patamar (educação e cultura e; direitos e desenvolvimento social), seguidos Estudos Geográficos, Rio Claro, 17: 116-133, jan./jun. 2019 (ISSN 1678-698X) http://www.periodicos.rc.biblioteca.unesp.br/index.php/estgeo 
de saúde, saneamento e acesso à água; gestão territorial; organização sustentável da produção; ações fundiárias.

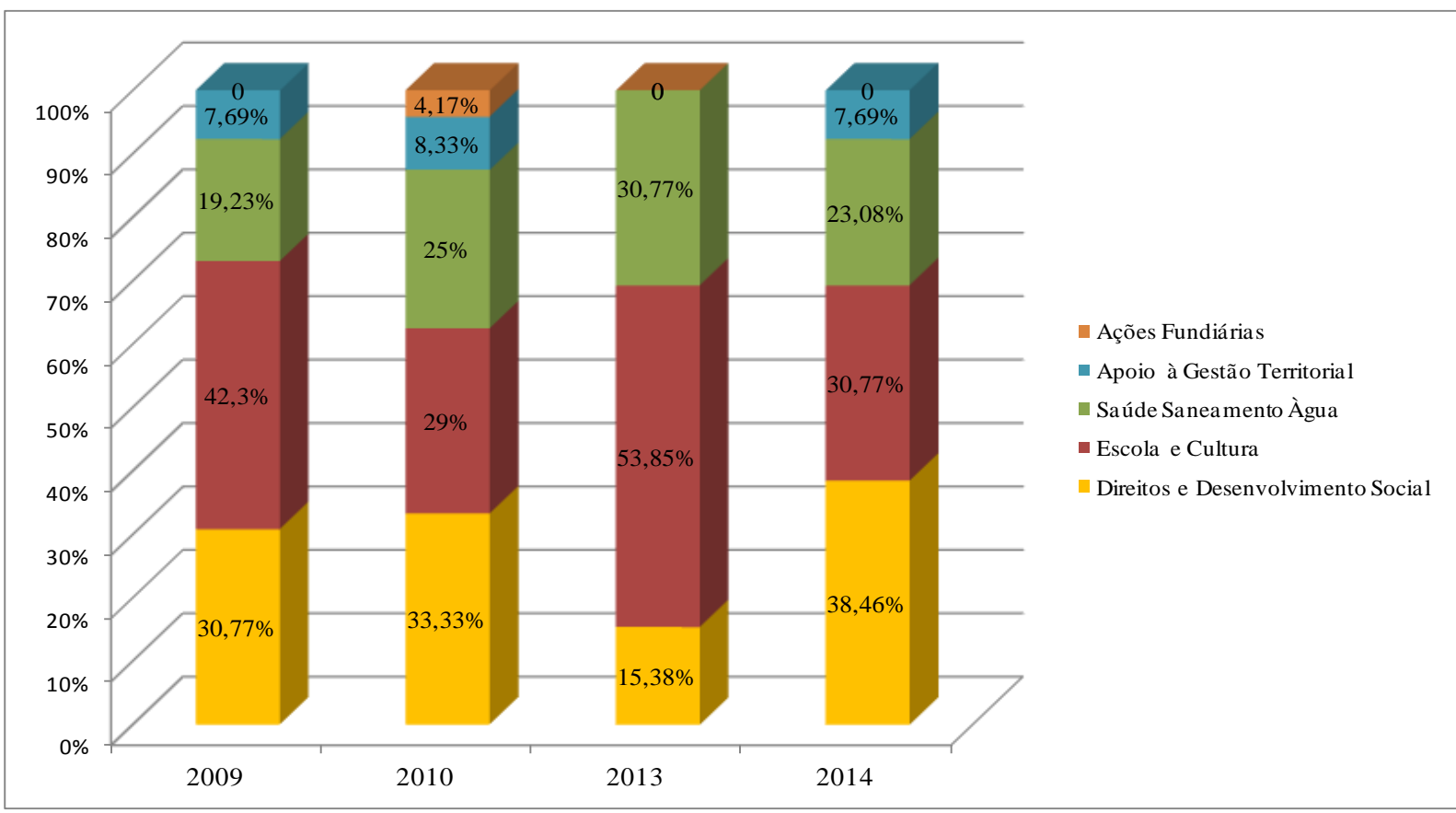

Gráfico 3 - Participação dos temas por número de ações por ano (2009 a 2014) no TC Sudeste

Fonte: Relatório de Execução 2009, 2010, 2013 e 2014.

No período de 2009 a 2010 e 2013 a 2014 foram implementadas 76 ações (programas) no eixo "Cidadania" no TC Sudeste. Estas ações contemplam majoritariamente as dimensões - ou temas, para usar a linguagem do PTC - de direitos e desenvolvimento social; educação e cultura; saúde, saneamento e acesso à água.

O gráfico 3 nos mostra que foi no segundo ano do Programa nesse Território (2010), que se deu a maior articulação entre temas, cinco dos sete tiveram ações/programas implementados(direitos e desenvolvimento social; educação e cultura; saúde, saneamento e acesso à água; apoio á gestão territorial e; ações fundiárias).

O tema apoio à gestão territorial teve participação com ações/ programas nos dois primeiros anos (2009 e 2010) e no último (2014).

O tema saúde, saneamento e acesso à água foi priorizado em todos os anos de implementação do Programa com um percentual variando ano a ano, entre 19\% e $30,77 \%$ das ações. Os temas educação e cultura e; direitos e desenvolvimento social também se articularam com os outros temas em todos os anos, e com o maior número de ações. A exceção se deu apenas no ano de 2013, quando o tema direitos e desenvolvimento social teve a menor participação. Neste ano de 2013, a priorização de ações foi majoritariamente do tema educação e cultura.

O tema ações fundiárias participa com 4,17\% da ações em 2010, ano que houve a maior articulação de temas.

No exercício de ordenamento das priorizações, que o gráfico 3 nos permite fazer, os temas ficam assim: educação e cultura; direitos e desenvolvimento social; saúde, saneamento e acesso à água; gestão territorial e; ações fundiárias.

Estudos Geográficos, Rio Claro, 17: 116-133, jan./jun. $2019 \quad$ (ISSN 1678-698X) http://www.periodicos.rc.biblioteca.unesp.br/index.php/estgeo 


\section{RESULTADOS}

Santos (2001) assevera que, na relação histórica entre atores hegemônicos e hegemonizados, para os primeiros o território usado "é um recurso, garantia da realização dos seus interesses particulares" e, para os segundos, o território usado é "abrigo, buscando constantemente se adaptar ao meio geográfico local, ao mesmo tempo que, recriam estratégias que garantam sua sobrevivência nos lugares".

As peculiaridades naturais, a cultura, a história, as diversidades sociais e políticas dos distintos territórios têm demonstrado que, apesar das várias tentativas de imprimir um único modelo de desenvolvimento ao mundo, o desenvolvimento é "processo de aprimoramento (gradativo ou, também, através de bruscas rupturas) das condições gerais do viver em sociedade, em nome de uma maior felicidade individual e coletiva", logo, ele é distinto para cada sociedade específica (SOUZA, 1996, p.9).

O modelo de desenvolvimento adotado por uma sociedade manifesta-se no tipo de cidadania do país. Ao Estado, como agente político, recai a responsabilidade de proporcionar as condições materiais e legais para o seu exercício. Se for o justo equilíbrio entre direitos e deveres na relação entre indivíduos e comunidade do território que se almeja como resultado do desenvolvimento, cabe ao Estado assegurar que os bens públicos deixem de ser exclusividade dos mais bem localizados.

Nesse estudo, pudemos ver que o Estado, por intermédio da política pública Programa Territórios da Cidadania, retoma seu papel de planejador do uso do território brasileiro - mesmo que, sem total autonomia em relação aos ditames do capitalismo mundial, que define $o$ uso do território com a intensidade e a temporalidade que lhe convém, regido pela necessidade de competitividade à escala do planeta - assumindo compromissos de proporcionar o uso mais igual do território aos segmentos sociais historicamente excluídos desse direito constitucional, neste caso especialmente, àquelas populações localizadas nos espaços rurais. O critério "possuir maior concentração de agricultores familiares e assentados da reforma agrária" para que o município integrasse um TC é um indicativo de que o governo re(sub)verte a lógica, sedimentada no país de políticas de criação de arranjos territoriais voltadas primordialmente para atender ao interesse do capital e das elites agrárias.

A análise socioeconômica que nos foi permitida fazer por meio dos indicadores de desenvolvimento humano (IDHM), que considera dados da educação, saúde e renda; do índice de Gini, que mede a desigualdade de renda entre as pessoas e; dos percentuais da população em situação de extrema pobreza (aquela que tem uma renda de até $1 / 4$ do salário mínimo) e em situação de vulnerabilidade à pobreza dos municípios que compõem os territórios da cidadania instituídos pela política no estado do Tocantins, leva-nos a concluir que, por uma construção histórica, naquelas regiões as pessoas não têm gozado de cidadania: não há justiça social nessas regiões.

A estratégia do governo federal de intervir nesses espaços de concentração de pobreza (para além da renda, constituída de múltiplas carências de serviços públicos e de ordem estrutural) imprime um novo exercício de cidadania ao país. Isso tem acontecido através da articulação de várias políticas, inclusive chamando à responsabilidade vários ministérios que, historicamente, voltaram-se para atender restritamente aos grupos hegemônicos - tais como o Ministério do Trabalho e

Estudos Geográficos, Rio Claro, 17: 116-133, jan./jun. 2019 (ISSN 1678-698X) http://www.periodicos.rc.biblioteca.unesp.br/index.php/estgeo 
Emprego, o Ministério das Cidades e o Ministério da Justiça. Mas acontece também pelo compartilhamento da gestão com outros entes federativos e com a sociedade civil organizada, de acordo com suas peculiaridades históricas de luta e formação territorial.

A variação das ações e do arcabouço institucional disponibilizado a cada um dos territórios no estado do Tocantins demonstraram que a participação da sociedade civil na gestão proporciona traçar o seu próprio modelo de desenvolvimento. A base para isso é o respeito à sua concepção e ao seu uso do território, considerando suas particularidades e seus anseios de coletividade.

A articulação entre ações de transferência de renda (que têm um impacto direto e de curto prazo sobre as condições materiais da pobreza) com outros programas, tais como a Educação do Campo, o Pronatec, a capacitação para a organização produtiva, as ações fundiárias, o programa de documentação da trabalhadora rural, o acesso à tecnologia de informação - a telemática - criam as condições reais de mobilidade social e geográfica para essa parcela da população brasileira.

O PTC modifica o espaço geográfico do estado do Tocantins inserindo um novo sistema de objetos e adequando os já existentes para assumirem novas funções no território tocantinense, que incluem infraestrutura de escolas, residências, eletrificação, plantios, maquinários, estradas, armazéns, torres de comunicação, entre outros. Ações também são implementadas, como capacitações, assistência técnica, educação, serviços de saúde, participação nas decisões da administração pública, etc. mesmo que a maioria das ações corresponda a intervenções rotineiras dos diferentes ministérios, o PTC propiciou uma maior concentração de recursos para os municípios que integram os territórios da cidadania, seja aumentando o orçamento das mesmas, seja proporcionando novas ações. Tendo em vista esses fatores, percebe-se que uma dinâmica de ampliação do acesso a bens e serviços de cidadania nesse espaço foi alcançada.

Assim, o PTC no estado do Tocantins se faz consoante ao que se verifica no seu conjunto em todo o território nacional. Segundo o balanço feito pelo governo federal, entre os anos de 2008-2014 foram instituídos 120 Territórios da Cidadania nas cinco regiões do País, com maior concentração no Nordeste e Norte, abrangendo 1.851 municípios, uma população de 44,6 milhões de habitantes, da qual $45,9 \%$ são rural (20,5 milhões de habitantes), 2,04 milhões de estabelecimentos da agricultura familiar, que correspondem a $46,9 \%$ do total e 6,03 milhões de agricultores familiares. Dentre o público atendido destacam-se também $637 \mathrm{mil}$ famílias dos assentados da reforma agrária (DEA/INCRA), 1.614 comunidades quilombolas (Fundação Cultural Palmares) e 508 mil famílias de pescadores (SINPESQ/Ministério da Pesca) (BRASIL, 2015).

Esses números revelam, por sua abrangência, que o PTC foi eficaz não apenas por ter alcançado de forma muito significativa o público para o qual o programa se destinou, como também pela redução das desigualdades sócioterritoriais, verificadas a partir da melhoria dos indicadores relativos ao público alvo. No entanto, é preciso uma pesquisa mais acurada que nos revele se o programa gozou de efetividade, tendo de fato contemplado aos interesses gerais do público ao qual se destinou.

Estudos Geográficos, Rio Claro, 17: 116-133, jan./jun. 2019 (ISSN 1678-698X) http://www.periodicos.rc.biblioteca.unesp.br/index.php/estgeo 


\section{REFERÊNCIAS}

ANDRADE, Pedro G.; STRAUCH, Julia C. M.; FERREIRA, Gustavo. Avaliação dos Critérios de Elegibilidade do Programa Territórios da Cidadania. Brasília, RESRRevista de Economia e Sociologia Rural, vol. 54, n. 4, p. 599 a 614, 2016.

BRASIL. Presidência da República. Decreto de 25 de fevereiro de 2008. Institui o Programa Territórios da Cidadania e dá outras providências. Brasília, DF, Diário Oficial [da] República Federativa do Brasil, Atos do Poder Executivo, 26 fev. 2008. Seção 1, p. 1.

Ministério do Desenvolvimento Agrário. Programa Territórios da Cidadania: Balanço 2008-2014. Brasília: MDA, 2015.

BUARQUE, Sérgio C. Políticas públicas de desenvolvimento territorial no Brasil: análise e sugestões de aprimoramento. In: BUARQUE, Sérgio C. (et. al.). Reflexões e proposições de políticas públicas de desenvolvimento territorial. Brasília: IICA, série "Desenvolvimento Rural Sustentável”, v.15, 2012, p.127-188.

DELGADO, N. G. Papel e lugar do rural no desenvolvimento nacional. Brasília: IICA/MDA/CONDRAF, 2009.

IBGE. Censo demográfico 1991, 2000 e 2010. Disponível em: HTTP://www.cidades.ibge.gov.br.

INCRA. Relatório de assentamentos 2014. Disponível em: http://www.painel.incra.gov.br/sistemas/index.php.

RAFFESTIN, Claude. A produção das estruturas territoriais e sua reprodução. In: Territórios e Territorialidades: teoria, processos e conflitos. In: SAQUET, Marco A.; SPOSITO, Eliseu S. (orgs.). Territórios e territorialidades: teorias, processos e conflitos. São Paulo: Expressão Popular, 2009, p.17-35.

SANTOS, M. O papel ativo da Geografia: um manifesto. Revista Bibliográfica de Geografia y Ciencias Sociales, Universidad de Barcelona, n. 270, p. 26-49, 2001.

SCHNEIDER, Sergio. Situando o desenvolvimento rural no Brasil: o contexto e as questões em debate. Revista de Economia Política, v.30, n. 3, p. 511 a 53, 2010.

SILVA, S. P. Avanços e limites na implementação de políticas públicas nacionais sob a abordagem territorial no Brasil. Rio de Janeiro: IPEA, 2013.

SOUZA, M. L. de. A teorização sobre o desenvolvimento em uma época de fadiga teórica, ou: sobre a necessidade de uma "teoria aberta" do desenvolvimento sócioespacial. Revista Território, Rio de Janeiro, v. 1, n. 1, p. 5-22, 1996.

www.palmares.gov.br.

www.sit.mda.gov.br

Estudos Geográficos, Rio Claro, 17: 116-133, jan./jun. $2019 \quad$ (ISSN 1678-698X) http://www.periodicos.rc.biblioteca.unesp.br/index.php/estgeo 